\title{
Importance of clinical posting for awareness on bio-medical waste in medical and paramedical students
}

Jemil S. Makadia, Anant Joshi, Mukesh G. Gohel

Department of Biochemistry, B J Medical College and Civil Hospital, Ahmedabad, Gujarat, India

Address for Correspondence: Dr. Jemil S. Makadia, Department of Biochemistry, $1^{\text {st }}$ Floor, B J Medical College and Civil Hospital, Ahmedabad,

Gujarat, India.

E-mail: jemil_sjm@yahoo.com

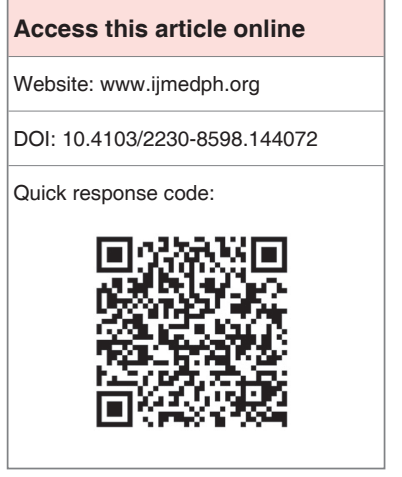

Background: The management of health care waste is the subject of considerable concern to public health. Unscientific disposal of health care waste may lead to the transmission of communicable disease which is a risk for health care professionals. Objective: The main objective of this study was to assess the awareness in the medical and paramedical students about bio-medical waste (BMW) hazards and management and to see the impact of clinical posting in knowledge regarding BMW handling. Materials and Methods: This was a cross-sectional type of study. A total of 240 subjects was enrolled, 60 each from $1^{\text {st }}$ year students of MBBS, BDS, nursing, and MLT. They were interviewed for health care waste management practices. Results: Study shows overall awareness regarding BMW in nursing and MLT students were better than MBBS and BDS students. We found that about the infection like HIV almost all the students were equally aware but awareness about hepatitis B infection was more in MBBS and BDS students and also in nursing students compared with MLT students. All the students from four groups were almost vaccinated for tetanus toxoid but only $50 \%$ students were vaccinated for hepatitis B. Conclusion: The nursing and MLT students comparatively were having better knowledge and attitude than BDS and MBBS students in many aspects. However, overall knowledge of $1^{\text {st }}$ year students from all the groups was not satisfactory and number of students those who were vaccinated for hepatitis B was also low which put them at risk.

Key words: Bio-medical waste, health care waste, hospital

\section{INTRODUCTION}

Bio-medical waste (BMW) is the term applied to the waste generated during the diagnosis, treatment or immunization of human beings or animals or in the research activities pertaining thereto or in the production or testing of biologicals and including categories viz. general waste, pathological waste, radioactive waste, chemical waste, infectious waste, sharps, pharmaceutical waste, pressurized containers. ${ }^{[1]}$

The management of health care waste is the subject of considerable concern to public health and infection-control specialists, as well as the general public. It is a well-known fact that in several types of health care activities, various types of hazardous and contagious materials are generated. Even though the consequences of discarding such waste carelessly are well-known, it is only recently that adequate initiatives to manage this waste in a scientific manner are being taken in India. Unscientific disposal of health care waste may lead to the transmission of communicable diseases such as gastroenteric infections, respiratory infections, spreading through air water, and direct human contact with the blood and infectious body fluids. These could be responsible for transmission of hepatitis B, C, E, and AIDS within the community. Health care professionals and the general public are at risk due to this. Diseases are spread by improper treatment and disposal of waste. ${ }^{[2]}$ Legal provisions (BMW [management and handling] Rules 1998) ${ }^{[1]}$ exist to mitigate the impact of hazardous and infectious hospital waste on the community. However, these provisions are yet to be fully implemented. The absence of proper waste management, lack of awareness about the health hazards from BMWs, insufficient financial and human resources, and poor control of waste disposal are the most critical problems connected with healthcare waste. The hazardous impact of medical waste on the public 
and environment is enhanced manifold if adequate and appropriate handling of these wastes is not adopted. ${ }^{[3]}$ Hence, bio-medical waste collection and proper disposal have become a significant concern for both the medical and the general community. ${ }^{[4,5]}$

Various studies on awareness of BMW across the country reveal that the awareness among health professionals about the hazards and its appropriate management techniques is unsatisfactory. ${ }^{[3,5,6]}$ Similar studies about the topic in the medical students and paramedical students are few. The medical and paramedical students during and after completing their studies are at potential risk for hazards due to BMW because of the contact with hospitals. Adequate knowledge about the health hazard of hospital waste and proper methods of handling is necessary to protect themselves, their patients as well as the community from various adverse effects of the hazardous waste. Considering all these aspects, this study was conducted with the main objective of assessing the awareness in the medical and paramedical students about BMW, its hazards and management.

\section{MATERIALS AND METHODS}

\section{Study subjects}

The study was conducted in the Department of Biochemistry, B J Medical College and Civil Hospital, Ahmedabad, Gujarat, India after getting approval from Institutional Ethical Committee. A total of 240 subjects was enrolled after written informed consent in our study, 60 each from $1^{\text {st }}$ year students of MBBS, BDS, BSc Nursing, and MLT.

\section{Study design and methods}

This study was a cross-sectional type of study. The aim was to study the awareness on BMW in $1^{\text {st }}$ year students from MBBS, BDS, BSc Nursing, and MLT at least after 6 months of admission in college. They were interviewed for health care waste management practices. Interviews were conducted on predesigned and pretested questionnaires and checklist. Data were collected and analyzed.

\section{RESULTS}

In the study, a total of 240 students was interviewed. It includes 60 each from $1^{\text {st }}$ year students of MBBS, BDS, BSc Nursing, and MLT after completion of 6 months in the study. When we try to find out knowledge of all the students on BMW and its handling, almost all the students from each group were aware of what is BMW. When they were asked about categories of waste only $15 \%$ of MBBS students, $19 \%$ of BDS students were aware of it but $53 \%$ of nursing and $40 \%$ of MLT students were aware of it. Even for color coding system for collection of BMW, awareness in nursing and MLT students were higher compare to MBBS and BDS students. $33 \%$ of MBBS students, $48 \%$ of BDS students, $85 \%$ of nursing students, and $78 \%$ of MLT students were able to answer satisfactorily about color coding system for BMW collection. On asking about disposal methods for BMW only $60 \%$ MBBS students, $50 \%$ BDS students,
47\% nursing students, and 52\% MLT students were able to answer it. This shows not much difference. When we try to know that how many of them can identify the symbol of BMW hazard, $58 \%$ of MBBS students, $82 \%$ of BDS students, $89 \%$ of nursing students, and $95 \%$ of MLT students were able to identify it [Table 1].

We try to assess the knowledge on hazards of BMW and its prevention for all the students. When we ask a question about infections due to BMW almost all the students from all groups knew about HIV infection but only 70\% MBBS students, $65 \%$ BDS students, $58 \%$ nursing students, and only 20\% MLT students knew about hepatitis B infection. On questioning about prevention from hazards due to BMW, it was found that almost About 90\% students were vaccinated for tetanus toxoid (TT) but $58 \%$ of MBBS students, $52 \%$ BDS students, $60 \%$ nursing students, and 39\% MLT students were vaccinated for hepatitis B. Almost 90\% were aware of methods of universal safety precautions. When we ask about postexposure prophylaxis for HIV, only 58\% MBBS students, $60 \%$ BDS students, $43 \%$ nursing students, and $52 \%$ MLT students knew about it [Table 2].

\section{DISCUSSION}

Bio-medical waste management needs systemic efforts, and it requires participation of all. There is much to be done where the waste is generated. The activities include reduction of waste generation, segregation, disposal, transportation, safety measures, and creating awareness, especially in hospital staff doctors, nurse,

\begin{tabular}{lcccc} 
Table 1: Awareness about BMW and its disposal \\
\hline Concept & \multicolumn{4}{c}{ Awareness $(\boldsymbol{n}=\mathbf{6 0}$ in each group) } \\
\cline { 2 - 6 } & $\begin{array}{c}\text { MBBS } \\
(\%)\end{array}$ & $\begin{array}{c}\text { BDS } \\
(\%)\end{array}$ & $\begin{array}{c}\text { Nursing } \\
(\%)\end{array}$ & $\begin{array}{c}\text { MLT } \\
(\%)\end{array}$ \\
\hline What is BMW? & $58(97)$ & $56(93)$ & $56(93)$ & $53(88)$ \\
Categories of BMW & $9(15)$ & $11(19)$ & $32(53)$ & $24(40)$ \\
Color coding system for & $20(33)$ & $29(48)$ & $51(85)$ & $47(78)$ \\
collection of BMW & & & & \\
Disposal methods for BMW & $36(60)$ & $30(50)$ & $28(47)$ & $31(52)$ \\
Symbol of BMW & $35(58)$ & $49(82)$ & $53(89)$ & $57(95)$ \\
\hline BMW = Bio-medical waste & & & &
\end{tabular}

\begin{tabular}{|c|c|c|c|c|}
\hline \multirow[t]{2}{*}{ Awareness on } & \multicolumn{4}{|c|}{ Awareness ( $n=60$ in each group) } \\
\hline & $\begin{array}{c}\text { MBBS } \\
(\%)\end{array}$ & $\begin{array}{l}\text { BDS } \\
(\%)\end{array}$ & $\begin{array}{c}\text { Nursing } \\
(\%)\end{array}$ & $\begin{array}{r}\text { MLT } \\
(\%) \\
\end{array}$ \\
\hline \multicolumn{5}{|l|}{ Infections } \\
\hline HIV & $58(97)$ & $57(95)$ & $59(98)$ & $55(92)$ \\
\hline Hepatitis B & $42(70)$ & $39(65)$ & $35(58)$ & $12(20)$ \\
\hline \multicolumn{5}{|l|}{ Vaccination } \\
\hline Hepatitis B & $35(58)$ & $31(52)$ & $36(60)$ & $23(39)$ \\
\hline TT & $56(93)$ & $52(87)$ & $51(85)$ & $54(90)$ \\
\hline Universal safety precautions & $56(93)$ & $54(90)$ & $56(93)$ & $52(87)$ \\
\hline $\begin{array}{l}\text { Postexposure prophylaxis } \\
\text { for HIV }\end{array}$ & $35(58)$ & $36(60)$ & $26(43)$ & $31(52)$ \\
\hline
\end{tabular}


technicians, housekeeping staff, and students or trainee. Knowledge about BMW management amongst the doctors, nurses, and technical staff found satisfactory in various studies. ${ }^{[3,6,7]}$

In our study, we tried to find out the difference in awareness and knowledge regarding BMW management and its hazards in $1^{\text {st }}$ year students of MBBS, BDS, Nursing, and MLT after 6 months of completion of course. Exposure of these students to the BMW in hospital during their clinical posting leads to more risk to them as they may not be trained properly. As nursing, MLT students have clinical posting in hospital from the beginning of course and BDS students have few clinical posting in its $1^{\text {st }}$ year, but MBBS students do not have much exposure in its clinical posting. Hence, our study also aim for to see the difference in awareness in these students after 6 months of course whether clinical posting of these students has any effect on knowledge of BMW management, as low level of knowledge is mainly attributed to poor training.

In our study, we observed that almost all the students were aware of what is BMW. But nursing and MLT students were more aware of practical part of BMW management than MBBS students. Even BDS students were more aware than MBBS students. Knowledge about categories of BMW, color coding system for segregation of BMW, and symbol for BMW hazards, were more in nursing and MLT students and also in BDS students compared to MBBS students.

On questioning on hazards of BMW and precautions to be taken to prevent it, we found that about the infection like HIV almost all the students were equally aware but awareness about hepatitis $\mathrm{B}$ infection was more in MBBS and BDS students and also in nursing students compared to MLT students. All the students from four groups were almost vaccinated for TT, but vaccination for hepatitis B was only about in 50\% students. Universal safety precautions are important to prevent hazards of BMW, so we ask it students and found that more than $90 \%$ students know what is it. But only $50 \%$ students in all groups were aware of post exposure prophylaxis for HIV.

Hence, in our study, we found overall awareness in nursing and MLT students were better than MBBS and BDS students. Knowledge and awareness in BDS students were more compare to MBBS students. Various other studies show different results. In a study by Suwarna and Ramesh 2012, ${ }^{[8]}$ found that in doctors and nurses knowledge about BMW was better than technicians. Sharma et al., 2013 ${ }^{[9]}$ a study conducted in Jaipur dental college where knowledge of dentists, nurses, and lab technicians were assessed, and they found it to be average and not satisfactory.

Being a cross-sectional study and we tried to assess the students very beginning in its carrier or learning process, it is difficult to say that what will be their awareness and attitude toward BMW in the future. But from this study, we can say that it is not only your theoretical knowledge about topic, but the practical aspect that is clinical posting in hospital has effect on your awareness and attitude toward BMW management.

\section{CONCLUSIONS AND RECOMMENDATIONS}

Lack of proper and complete knowledge about BMW management impacts practices of appropriate waste disposal and put health care workers at the risk.

The nursing and MLT students comparatively were having better knowledge and attitude than BDS and MBBS students in many aspects. But overall knowledge of $1^{\text {st }}$ year students from all the groups was not satisfactory and number of students those who were vaccinated for hepatitis B was also low which put them at risk of biohazards.

Following recommendations are proposed:

1. It should be made compulsory for medical and paramedical institute to train their students and trainee before they start their clinical posting in hospital not just by lectures but also by demonstration. These training sessions should not become merely a 1-time activity but should be a continuous process depending upon the patient input in different healthcare facilities.

2. Students and staff of the institute should be vaccinated against hepatitis $B$ and other infectious disease preferably it should be a part of health checkup after admission process.

\section{REFERENCES}

1. Government of India. Biomedical Waste (Management and Handling) Rules. 1998. Extraordinary, Part II, Section3, Subsection (ii). The gazette of India, No. 460,27 July; 1998.

2. Gujarat Pollution Control Board, Gandhinagar. Biomedical Waste Management, 2005. p. 2.

3. Mathur V, Dwivedi S, Hassan M, Misra R. Knowledge, Attitude, and Practices about Biomedical Waste Management among Healthcare Personnel: A Cross-sectional Study. Indian J Community Med 2011;36:143-5.

4. Central Pollution Control Board, Environmental Standard and Guidelines for Management of Hospital Waste. CPCB, Ministry of Environment and Forest, New Delhi, Jun 1996.

5. Yadavannavar M, Berad AS, Jagirdar P. Biomedical waste management: A study of knowledge, attitude, and practices in a tertiary health care institution in bijapur. Indian J Community Med 2010;35:170-1.

6. Pandit NB, Mehta HK, Kartha GP, Choudhary SK. Management of biomedical waste: Awareness and practices in a district of Gujarat. Indian J Public Health 2005;49:245-7.

7. Saini S, Nagarajan SS, Sarma RK. Knowledge; attitude and practices of bio-medical waste management amongst staff of a tertiary level hospital in India. J Acad Hosp Adm 2005;17:2.

8. Suwarna M, Ramesh G. Study about awareness and practices about health care Wastes management among hospital staff in a medical college hospital, Bangalore. Int J Basic Med Sci 2012;3:7-11.

9. Sharma A, Sharma V, Sharma S, Singh P. Awareness of biomedical waste management among health care personnel in Jaipur, India. Oral Health Dent Manag 2013;12:32-40.

How to cite this article: Makadia JS, Joshi A, Gohel MG. Importance of clinical posting for awareness on bio-medical waste in medical and paramedical students. Int $\mathrm{J}$ Med Public Health $2014 ; 4: 377-9$

Source of Support: Nil, Conflict of Interest: None declared. 